\title{
Potencial de economia de água em duas escolas em Florianópolis, SC
}

\author{
Potential for potable water savings in two schools in \\ Florianópolis, SC
}

\section{Gabriel Balparda Fasola \\ Enedir Ghisi \\ Ana Kelly Marinoski J affer Bressan Borinelli}

Gabriel Balparda Fasola Departamento de Engenharia Sanitária e Ambiental Universidade Federal de Santa Catarina

Florianópolis - SC - Brasil

Caixa Postal S/ N CEP 88113-820

E-mail: gabrielbalparda@hotmail.com

Enedir Ghisi Laboratório de Eficiência Energética em Edificações, Departamento de

Engenharia Civil

Universidade Federal de Santa

Caixa Postal 476

Florianópolis - SC - Brasil

CEP 88040-900

Tel.: (48) 3721-5536

E-mail: enedir@labeee.ufsc.br

Ana Kelly Marinoski Laboratório de Eficiência Energética em Edificações, Departamento de Engenharia Civil

Universidade Federal de Santa Catarina

E-mail: anakmarinoski@gmail.com

J affer Bressan Borinelli Departamento de Engenharia Civil Universidade Federal de Santa Catarina E-mail: jafferborinelli@gmail.com

Recebido em 20/08/11 Aceito em 19/11/11

\section{Resumo}

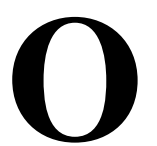

objetivo deste artigo é apresentar os usos finais de água potável estimados e o potencial de economia de água potável obtido por meio de um sistema de aproveitamento de água pluvial, reúso de águas cinzas, equipamentos economizadores, ou combinação deles, em duas escolas do município de Florianópolis, Santa Catarina. Para isso, foi necessário obter informações sobre os hábitos de consumo dos ocupantes e realizar medições de vazão e levantamento de dados e aparelhos sanitários das escolas (uma estadual e outra municipal). Para o cálculo do potencial de economia obtido através do aproveitamento de água pluvial utilizou-se o programa Netuno 2.1. No reúso de águas cinzas, consideraram-se como oferta de água para a escola municipal os efluentes provenientes das torneiras de banheiros e da máquina de lavar roupas, e para a escola estadual foram considerados apenas os efluentes provenientes das torneiras de banheiros. Por último, as reduções de consumo de água potável, decorrentes da instalação de equipamentos economizadores, foram avaliadas para bacias sanitárias, mictórios, torneiras comuns e torneiras de fechamento automático. Como resultado, obteve-se um consumo de 28,8 litros/pessoa.dia na escola municipal, e de 25,3 litros/pessoa.dia na escola estadual. Com relação aos usos finais, as torneiras da cozinha e os mictórios destacaram-se como os maiores responsáveis pelo consumo de água. No que se refere ao potencial de economia de água, o resultado mais expressivo foi de $27,8 \%$ para a escola municipal e de $72,7 \%$ para a escola estadual, combinando equipamentos economizadores e aproveitamento de água pluvial.

Palavras-chave: Uso final de água. Economia de água potável. Escola.

\section{Abstract}

The objective of this article is to present potable water end-uses and assess the potential for potable water savings by using rainwater, reusing greywater, using water-saving plumbing fixtures, and their combination, in two schools located in Florianópolis, Santa Catarina. Thus, it was necessary to obtain information about the water consumption habits of users and to perform water flow measurements and data survey in the schools. The Netuno 2.1 computer programme was used to estimate the potential for potable water savings obtained by rainwater harvesting. As for greywater reuse, the water supply from toilet taps and one washing machine were considered in one of the schools, and toilet taps in the other. Potable water savings due to water-saving plumbing fixtures were evaluated for toilet flushing, urinals and taps. Potable water consumption of 28.8 litres/person.day and 25.3 litres/person.day were obtained in each school. As for the potable water end-uses, kitchen taps were responsible for the highest water consumption level in one school, and urinals in the other. With regards to the potential for potable water savings, the best result was $27.8 \%$ for one school and $72.7 \%$ for the other, through combining water-saving plumbing fixtures and rainwater harvesting.

Keywords: Potable water savings. Water end-uses. Schools. 


\section{Introdução}

A água é um recurso essencial para a promoção do desenvolvimento e da qualidade de vida, porém nos últimos anos $\mathrm{o}$ acelerado crescimento populacional e a crescente industrialização têm aumentado o consumo de água, acarretando graves pressões aos recursos hídricos (UNITED..., 2002).

Crises no abastecimento de água estão-se tornando cada vez mais frequentes em muitos locais devido à falta de gerenciamento adequado, mudanças nos hábitos de consumo da população, períodos de estiagens e também à própria escassez desse bem (GONÇALVES, 2006).

As mudanças climáticas globais possuem também implicações diversas quanto à disponibilidade de recursos hídricos nas diferentes regiões do planeta, tornando a disponibilidade de água nas bacias hidrográficas cada vez mais complexa (ANDRADE; MARINOSKI; BECKER, 2010).

Outro fator preocupante é o grande desequilíbrio entre oferta de água e demanda, ocasionado pela distribuição irregular da água pelo mundo. No Brasil, por exemplo, a região Norte, que compreende a Bacia Amazônica, detém cerca de $70 \%$ da água brasileira, e a população naquela região representa somente $8 \%$ da população nacional. Em contraste, a região Sudeste abriga $43 \%$ da população, porém apresenta apenas $6 \%$ da água disponível no país (GHISI, 2006).

Não obstante, alternativas vêm sendo utilizadas para diminuir a demanda e racionalizar o consumo de água. Entre essas tecnologias destacam-se o aproveitamento de água pluvial, o reúso de águas cinzas e o emprego de equipamentos economizadores de água.

O aproveitamento de água pluvial é uma prática milenar, empregada no mundo todo. Dependendo da região, apresenta bons resultados de economia de água potável (TOMAZ, 2003).

O reúso de águas cinzas consiste na reutilização, após tratamento adequado, de efluentes provenientes de tanques, banheiras, chuveiros, lavatórios e máquinas de lavar roupas em residências, escritórios comerciais, escolas, entre outros (ANA, 2005).

Gonçalves (2006) salienta que, embora aporte um impacto significativo na redução de consumo de água (em média $15 \%$ a $30 \%$ ), o reúso de águas cinzas demanda um investimento significativo nas edificações, tanto na fase de projeto como nas que necessitam de reforma para implementação, o que representa um custo-benefício baixo.

$\mathrm{O}$ uso de equipamentos economizadores, tais como torneiras hidromecânicas, redutores de vazão, sensores e válvulas de descarga com acionamento seletivo, é a alternativa que mais vem crescendo no país (PROGRAMA..., 2006).

A fim de minimizar o consumo de água nas edificações, diversos estudos (MANO; SCHMITT, 2004; SIMIONI et al., 2004; PHILIPPI et al., 2005; GHISI; OLIVEIRA, 2007) vêm sendo desenvolvidos em diversas tipologias de edificações para verificar os usos finais de água e avaliar a economia de água obtida mediante o aproveitamento de água pluvial, reúso de águas cinzas e uso de equipamentos economizadores.

No setor residencial, Barreto (2008) realizou um levantamento do perfil de consumo e usos finais da água em uma amostra de sete residências localizadas em São Paulo, SP. Verificou-se que o ponto de utilização de maior consumo de água é o chuveiro, com $13,9 \%$ do total consumido, seguido da torneira de pia da cozinha, com 12,0\%.

Peters et al. (2006) avaliaram o potencial de reúso de água cinza combinada com água pluvial em uma residência unifamiliar em Florianópolis, SC. A partir dos resultados obtidos observou-se que a água pluvial possui qualidade superior à água cinza, apresentando potencial de utilização na lavagem de roupas. A produção regular de águas cinzas na residência superou a demanda de água na bacia sanitária, podendo ser utilizada também em outros usos não potáveis, tais como rega de jardim e lavagem de veículos, não havendo a necessidade de misturá-las com outra fonte alternativa.

Sautchúk (2004) analisou o potencial de redução da demanda de água potável de um edifício de escritórios localizado em São Paulo, SP, mediante a instalação de equipamentos economizadores e medição individualizada. Foi verificada a possibilidade de redução de $30 \%$ no consumo de água potável. Além disso, verificou-se que o potencial de redução no consumo de água potável seria de $34 \%$ caso fosse realizado aproveitamento de água pluvial (para usos em bacias sanitárias, lavagem de áreas externas e irrigação) aliado à otimização de consumo.

Quanto à tipologia escolar, em um estudo realizado por Ghisi e Marinoski (2008), foram estimados os usos finais de água de uma instituição de ensino em Florianópolis por meio de entrevistas com usuários e medição de vazões de aparelhos sanitários. A partir desses dados constatou-se que $63,5 \%$ dos usos finais são utilizados para fins não potáveis, o que poderia ser realizado com água pluvial. Além disso, verificou-se, com o auxílio do programa computacional Netuno (GHISI; CORDOVA; ROCHA, 2009), que o potencial de 
economia de água potável obtido com a implantação de um sistema de aproveitamento de água pluvial naquela instituição de ensino seria de $45,8 \%$.

Fonini, Fernandes e Pizzo (2004) quantificaram o volume de água pluvial e águas cinzas com possibilidade de reaproveitamento para fins não potáveis em um complexo esportivo universitário em Passo Fundo, RS. O volume de água pluvial passível de ser aproveitado foi de $186 \mathrm{~m}^{3} / \mathrm{mês,} \mathrm{o}$ qual, após tratamento adequado, seria suficiente para suprir o consumo de água para a manutenção da piscina do local. Verificou-se que as águas cinzas provenientes dos chuveiros existentes geram um montante de aproximadamente 106 $\mathrm{m}^{3} /$ mês, volume suficiente para abastecer as caixas acopladas das bacias sanitárias e promover a limpeza de ambientes.

O maior estudo encontrado na literatura brasileira referente a usos finais de água em escolas está pautado em uma pesquisa em uma amostra de 87 escolas de diferentes tipologias que compõem a rede pública de Campinas, SP. Nessa pesquisa, foram observados três tipos de escolas: Centro Municipal de Educação Infantil (Cemei), que atende crianças de até 4 anos; Escola Municipal de Educação Infantil (Emei), que atende crianças de 5 e 6 anos); e Escola Municipal e Estadual de Ensino Fundamental (Emef). Foram identificados todos os tipos de consumo de água em cada ambiente das escolas estudadas e também por aparelho sanitário, e verificou-se que os banheiros são responsáveis pelas maiores parcelas de consumo de água nas escolas; o segundo maior consumidor de água é a cozinha; a área externa é responsável pelas menores parcelas do consumo (YWASHIMA, 2005; YWASHIMA et al., 2006; GONÇALVES et al., 2005).

Werneck e Bastos (2006) realizaram um estudo para avaliar a viabilidade do uso de água pluvial para fins não potáveis em 77 escolas do município de Barra do Piraí, RJ. Nessa pesquisa, realizou-se um estudo de caso para avaliar a viabilidade de instalação de um sistema de aproveitamento de água pluvial em um colégio particular, o Colégio Cândido Mendes. Para tanto, adotou-se um percentual de $70 \%$ da demanda total de água para usos não potáveis, valor entre os apresentados por Ywashima (2005) para as escolas de ensino fundamental. Os autores verificaram que o consumo de água potável no colégio avaliado poderia ser reduzido em $40,4 \%$ mediante a implantação de um sistema de aproveitamento de água pluvial, enquanto, através do uso conjunto de equipamentos economizadores e aproveitamento de água pluvial, o consumo seria reduzido em $64,4 \%$.
Com relação ao consumo de água em instituições de ensino, é importante ressaltar que ele pode variar bastante devido aos tipos de aparelhos sanitários e às dependências existentes no local, como lanchonetes, ginásios, laboratórios, cozinha, horta e outros ambientes em que ocorre consumo de água. Além disso, de acordo com Gonçalves (2006), vários fatores influenciam no consumo de água, dos quais se destacam o clima da região, renda familiar, características culturais e valores das tarifas.

Tendo em vista que as escolas são exemplos de instituições que pertencem ao setor público, onde são contabilizados maiores consumos e desperdícios de água, mostra-se cada vez mais importante o incentivo à conservação de água nessa tipologia de edificações.

Além disso, as escolas atendem direta ou indiretamente um grande número de pessoas, sendo, portanto, um excelente meio de divulgação dos benefícios do emprego de técnicas sustentáveis como o aproveitamento de água pluvial, o reúso de águas cinzas e a instalação de equipamentos economizadores.

O objetivo deste artigo é apresentar os usos finais de água estimados e o potencial de economia de água potável obtido por meio do aproveitamento de água pluvial, reúso de águas cinzas, uso de equipamentos economizadores e combinação entre essas estratégias em duas escolas localizadas em Florianópolis, SC.

\section{Método}

As escolas consideradas na pesquisa são a Escola Desdobrada Osvaldo Galupo e a Escola de Ensino Básico Silveira de Souza, denominadas neste estudo de escola municipal e escola estadual respectivamente. Ambas estão localizadas no centro de Florianópolis, SC.

A escola municipal atualmente atende da creche até a $4^{\underline{a}}$ série, com 170 alunos por ano em média, e conta com 12 professores e cinco funcionários. A escola estadual atualmente atende às séries préescolares até a $4^{\underline{a}}$ série e poucas séries de $5^{\mathrm{a}}$ a $8^{\mathrm{a}}$, com uma média de 230 alunos por ano, tendo em seu quadro 18 professores e cinco funcionários.

Como em uma escola pode haver várias faixas etárias, escolheu-se a faixa dos 8 aos 12 anos para a aplicação dos questionários, por se acreditar que essa faixa etária forneceria uma resposta mais coerente. As séries que compreendem essa faixa são as de $3^{\underline{a}}$ a $5^{\underline{a}}$ do ensino fundamental. Então, solicitou-se às Secretarias Municipal e Estadual de Educação a lista das escolas públicas com esse tipo 
de ensino. Entre as disponíveis e interessadas na pesquisa, duas foram selecionadas.

\section{Determinação da amostra}

Embora se tenha procurado obter hábitos de consumo de praticamente todos os ocupantes das escolas, isso não foi possível com toda a população de alunos. As amostras de alunos foram calculadas segundo a metodologia apresentada por Barbetta (2003), que salienta que é possível determinar uma amostra que represente determinado número de pessoas através da Equação 1.

$n \geq \frac{n \mathrm{O} * \mathrm{~N}}{n \mathrm{O}+\mathrm{N}}$

Eq. 1

Para:

$n \mathrm{o} \geq \frac{1}{\varepsilon_{0}^{2}}$,

Onde:

n é o número de pessoas da amostra a serem entrevistadas;

$\mathrm{N}$ é o número total de pessoas; $\mathrm{e}$

$\varepsilon_{0}$ é o erro amostral desejado ( $1 \%$ a $20 \%$ ).

Para uma amostra ser bastante significativa, o erro adotado deveria estar entre $1 \%$ e $4 \%$ (BARBETTA, 2003). Porém, para este estudo foram adotados valores maiores de erros, em função do número de pessoas que efetivamente poderiam ser entrevistadas devido à faixa etária.

\section{Levantamento de dados}

Inicialmente, foi realizado, com apoio da administração escolar de cada escola, um levantamento dos dados gerais das escolas, como o número de ocupantes, períodos de funcionamento e espaços físicos.

Para estimar os usos finais de água nas escolas e assim obter o potencial de economia, foi necessário realizar levantamentos de dados sobre hábitos de consumo de água.

Primeiramente, realizaram-se visitas in loco para inspeção e levantamento dos tipos de aparelhos sanitários existentes nas escolas analisadas, estado de conservação, quais as atividades de higiene e limpeza realizadas, como elas são desempenhadas e quais aparelhos sanitários são utilizados nessas atividades. Além disso, mediante vistoria nos aparelhos sanitários, verificou-se também se existiam vazamentos visíveis.

Também foram realizadas entrevistas com os ocupantes das escolas por meio de questionários diferenciados para funcionários, professores e alunos. Ressalta-se que os questionários aplicados na escola municipal eram diferentes dos da escola estadual, pois as escolas apresentam tipos de aparelhos sanitários diferentes.

Nos questionários foram feitas perguntas que demonstrassem o tempo e a frequência de uso que cada aparelho sanitário era utilizado no período de ocupação da escola.

$\mathrm{O}$ consumo médio mensal medido de água das duas escolas foi obtido mediante histórico de consumo verificado nas faturas da concessionária de abastecimento de água para um período de dois anos e oito meses (agosto de 2006 a abril de 2009).

\section{Consumo estimado}

O consumo estimado de água foi obtido por meio de questionários aplicados aos alunos durante um período de cinco dias e entrevistas com todos os funcionários e professores.

Para o cálculo do consumo estimado de água com o uso das torneiras, cozinha, bebedouros e bacias sanitárias com válvula de descarga, utilizou-se a Equação 2 .

$\mathrm{C}_{\mathrm{ap}}=f^{*} t * Q$

Eq. 2

Onde:

C é o consumo de água de cada usuário por aparelho sanitário (litros/dia);

f é a frequência média de utilização (vezes/dia);

t é o tempo médio de cada utilização (segundos/vez); e

Q é a vazão média do dispositivo (litros/segundo).

Para o cálculo do consumo de água através do uso de bacias sanitárias com caixa de descarga e torneiras de fechamento automático, utilizou-se a Equação 3 .

$\mathrm{C}_{\mathrm{ap}}=f^{*} A * V$

Eq. 3

Onde:

C é o consumo de água de cada usuário para cada aparelho (litros/dia);

f é a frequência média de utilização para cada aparelho (vezes/dia);

A é o número médio de acionamentos do dispositivo ao utilizá-lo (acionamentos/vez); e

V é o volume médio de água armazenado na caixa de descarga ou volume despejado pela torneira (litros/acionamento).

A quantidade de água utilizada na limpeza foi medida em baldes, por ser a forma mais comum de limpeza utilizada. Logo, como forma de padronizar o consumo de água com essa atividade, mediu-se a 
quantidade de água utilizada para encher um balde. Para o cálculo do consumo com limpeza por dia utilizou-se a Equação 4.

$\mathrm{C}_{\text {limpeza }}=f * N_{\mathrm{o}} * V_{\text {baldes }}$

Eq. 4

Onde:

$\mathrm{C}_{\text {limpeza }}$ é o consumo diário para limpeza da escola (litros/dia);

f é a frequência com que é feita a limpeza (vezes/dia);

№ é a quantidade de baldes utilizados para executar a limpeza (№/vez); e

$\mathrm{V}_{\text {baldes }}$ é o volume do balde utilizado (litros).

Para a escola municipal, a limpeza do ambiente inclui também o consumo diário referente a uma máquina de lavar roupas. $\mathrm{O}$ consumo de água proveniente da máquina de lavar roupas foi estimado com base na frequência de utilização (vezes por semana) e no volume de água consumido no ciclo completo de lavagem (litros/lavagem). Nessa análise, foi adotado o consumo semanal, e então dividido pelo número de dias da semana para a obtenção do consumo diário, de acordo com a Equação 5.

$\mathrm{C}_{\text {máq_lavar }}=\frac{\mathrm{N}^{*} \mathrm{~V}_{m a ́ q}}{7}$

Onde:

$\mathrm{C}_{\text {máq lavar }}$ é o consumo de água diário a partir da máquina de lavar roupas (litros);

$\mathrm{N}$ é a frequência de uso semanal da máquina de lavar roupas (vezes/semana); e

$\mathrm{V}_{\text {máq }}$ é o volume máximo de água consumido no ciclo completo de lavagem na máquina de lavar roupas (litros);

Por fim, para o cálculo do consumo diário na escola utilizou-se a Equação 6.

$\mathrm{C}_{\text {diáro }}=\left(\mathrm{C}_{\text {aluno }} * \mathrm{~N}_{\text {alunos }}\right)+\left(\mathrm{C}_{\text {prof }} * \mathrm{~N}_{\text {prof }}\right)+$

$\left(\mathrm{C}_{\text {func }} * \mathrm{~N}_{\text {func }}+\mathrm{C}_{\text {limpeza }}+\mathrm{C}_{\text {cozinha }}\right)$

Eq. 6

Onde:

Cdiário é o consumo diário na escola (litros/dia);

Caluno é o consumo diário do aluno obtido por meio das Equações 2 e 3 (litros/dia.aluno);

Nalunos é o número total de alunos da escola;

Cprof é o consumo diário dos professores obtido por meio das Equações 2 e 3 (litros/dia.professor);

$\mathrm{N}_{\text {prof }}$ é o número total de professores da escola;

$\mathrm{C}_{\text {func }}$ é o consumo diário dos funcionários obtido por meio das Equações 2 e 3

(litros/dia.funcionário);
$\mathrm{N}_{\text {func }}$ é o número total de funcionários da escola;

$\mathrm{C}_{\text {limpeza }}$ é o consumo diário para limpeza da escola (litros/dia); e

$\mathrm{C}_{\text {cozinha }}$ é o consumo diário da cozinha para produção da merenda da escola (litros/dia).

O consumo mensal de água foi separado em dois períodos distintos: período letivo e período de férias. Como nos meses de férias o consumo de água das escolas se refere a atividades não cotidianas de difícil mensuração, não foram estimados os consumos respectivos a esse período. Logo, para efeitos de comparação são consideradas apenas as médias do consumo no período letivo apresentadas no histórico de faturas obtido.

Excluindo-se os fins de semana e feriados nacionais e locais, há, em média, na cidade de Florianópolis 20,75 dias úteis por mês. Assim, os consumos mensais de água foram calculados utilizando-se a Equação 7.

$\mathrm{Cm}_{\text {letivo }}=\mathrm{C}_{\text {diário }} * 20,75$

Eq. 7

Onde:

$\mathrm{Cm}_{\text {letivo }}$ é o consumo mensal de água na escola durante o período letivo ( $\left.\mathrm{m}^{3} / \mathrm{mês}\right)$; e

$\mathrm{C}_{\text {dírio }}$ é consumo diário de água na escola $\left(\mathrm{m}^{3} / \mathrm{dia}\right)$.

A vazão média utilizada nos cálculos foi medida cronometrando-se o tempo em que a água levava para encher determinado volume em um recipiente graduado. Isso foi aplicado para os bebedouros e as torneiras da edificação. As torneiras de fechamento automático foram medidas anotandose os volumes totais despejados a cada acionamento.

Para as bacias sanitárias equipadas com válvula de descarga adotou-se a vazão de 1,7 litro/segundo, e para mictórios, de 0,15 litro/segundo, valores recomendados pela norma NBR 5626 (ABNT, 1998). Para esses aparelhos foi medido o tempo a partir do acionamento até o encerramento da liberação de água para que se pudesse calcular o volume. Para as bacias sanitárias com caixa acoplada, verificou-se a capacidade de armazenamento da caixa ou buscaram-se informações com o fabricante. As vazões e os volumes de caixa de descarga foram usados no cálculo dos consumos específicos.

\section{Análise de sensibilidade}

Como as estimativas de consumo e de usos finais de água são feitas com base nas respostas dos ocupantes das escolas e estão sujeitas a erros, foi realizada uma análise de sensibilidade a fim de verificar a influência de cada aparelho sobre o 
consumo final e determinar quais são os aparelhos mais sensíveis a erros.

Aplicaram-se variações de $-20 \%$ a $+20 \%$, em intervalos de $10 \%$, sobre a frequência, vazão e tempo de uso dos aparelhos que possuíam os maiores consumos de água nas escolas.

Assim, os usos finais estimados foram comparados aos usos finais após as correções nos consumos específicos mais sensíveis apontados pela análise de sensibilidade. Então se avaliou a influência da aplicação dessa análise quantificando-se a diferença (em percentual e em litros) nos dois usos finais estimados mais sensíveis (antes e após a análise de sensibilidade) para cada escola.

De acordo com os resultados da análise de sensibilidade, ajustou-se o consumo estimado para que se igualasse ao consumo médio obtido nas faturas de água.

\section{Usos finais}

Depois de realizada a análise de sensibilidade e feita a comparação entre o consumo estimado e o consumo medido para confirmar se os dados estavam corretos, foi possível estimar os usos finais de água.

Para a estimativa dos usos finais de água fez-se necessário classificar os consumos de água potável de acordo com os tipos de atividade e aparelhos sanitários mais comuns nas duas escolas, a saber: torneiras de banheiro, bacia sanitária, mictório, cozinha, bebedouro, limpeza e máquina de lavar roupas.

Posteriormente a isso, classificaram-se os consumos de água das escolas em usos potáveis e usos não potáveis. Os usos potáveis referem-se aos usos que necessitam estar dentro dos padrões de potabilidade, ou seja, cozinha, bebedouro, torneiras de banheiro. Os usos não potáveis foram definidos como descarga de bacias sanitárias, mictórios e limpeza.

Mediante a soma dos percentuais de consumo de água na categoria de usos não potáveis (descargas de bacias sanitárias, mictórios e limpeza da escola), verificou-se o percentual de água potável que poderia ser substituído por água pluvial.

Com base nos dados de usos finais de água das torneiras dos banheiros e máquina de lavar roupas, foi verificado o potencial de economia de água potável nas escolas através do reúso das águas cinzas provenientes desses aparelhos.

\section{Estratégias para redução do consumo}

Foram analisadas três estratégias (aproveitamento de água pluvial, reúso de águas cinzas e instalação de equipamentos economizadores) para a redução do consumo de água potável e algumas combinações entre elas.

\section{Aproveitamento de água pluvial}

Para simular a implantação de um sistema de aproveitamento de água pluvial nas escolas analisadas, foi utilizado o programa computacional Netuno 2.1 (GHIS; CORDOVA; ROCHA, 2009). O programa Netuno indica o volume ideal de reservatório de acumulação da água pluvial e o potencial de economia de água potável obtido pelo uso de água pluvial.

Os dados de entrada do programa são: área de captação, dados diários de precipitação pluviométrica, percentual de água potável que poderia ser substituído por água pluvial, demanda diária de água potável, número de ocupantes, coeficiente de aproveitamento, volume do reservatório superior de água pluvial.

A verificação das áreas de captação de água pluvial foi realizada com base nas áreas de telhado verificadas na planta de cobertura de cada escola, de acordo com as respectivas inclinações dos telhados.

Os dados pluviométricos utilizados foram fornecidos pela Empresa de Pesquisa Agropecuária e Extensão Rural de Santa Catarina S.A. (Epagri), coletados da Estação Meteorológica de Florianópolis. Os dados fornecidos incluem informações sobre precipitações diárias de sete anos, de 01/01/2000 a 31/12/2006.

O coeficiente de aproveitamento é utilizado para representar o volume aproveitável de água pluvial após o desvio de escoamento inicial para descarte de folhas e detritos, e também as perdas por absorção e evaporação da água pluvial ao atingir a superfície de captação. Nesta pesquisa utilizou-se coeficiente de aproveitamento de $80 \%$, ou seja, $20 \%$ de perdas no processo de captação da água pluvial.

A demanda diária de água pluvial é a demanda de água potável que se deseja substituir por pluvial e foi obtida por meio da estimativa de usos finais. Conforme descrito anteriormente, considerou-se que a água utilizada em descargas de bacias sanitárias, mictórios e limpeza da escola poderia ser substituída por água pluvial.

Como o programa Netuno possui a opção de especificar os diferentes consumos em cada dia, caso a edificação apresente demanda variável de

70 Fasola, G. B.; Ghisi, E.; Marinoski, A. K.; Borinelli, J. B. 
água (variação do consumo de acordo com o dia da semana), para as escolas estudadas, considerou-se que só há consumo de água durante os dias úteis da semana.

\section{Reúso de águas cinzas}

O potencial de economia de água potável obtido nas escolas por meio do reúso de águas cinzas foi calculado considerando-se como oferta os efluentes das torneiras dos banheiros e máquina de lavar roupas. Tal oferta de água foi utilizada para diminuir a demanda diária das bacias sanitárias e mictórios.

\section{Aparelhos economizadores}

Para estimar a redução de consumo com a instalação de equipamentos economizadores, foi prevista a substituição de torneiras, bacias sanitárias e mictórios. Como existem vários equipamentos, optou-se por duas tecnologias distintas: uma sensorial (sensor de presença) e outra hidromecânica (fechamento automático).

Para as bacias sanitárias, utilizou-se a descarga dual. Essa descarga possibilita o despejo de três ou seis litros de água por acionamento. Considerandose que a utilização da descarga de três litros é mais frequente do que a utilização da descarga de seis litros, estimou-se que em $90 \%, 70 \%$ e $50 \%$ de utilizações da descarga o acionamento seria o de três litros. Para estimar a redução proveniente do sistema dual em bacias sanitárias utilizou-se a Equação 8.

$\mathrm{C}_{\text {novovs }}+\left(f^{*} \alpha_{6} * V_{6}\right)+\left(f^{*} \alpha_{3} * V_{3}\right)$

Eq. 8

Onde:

$\mathrm{C}_{\text {novo vs }}$ representa o novo consumo diário da bacia sanitária (litros/dia); f é a frequência de uso da bacia sanitária (vezes/dia);

$\alpha_{6}$ representa a porcentagem de utilizações da descarga de seis litros, que pode ser de $10 \%, 30 \%$ e $50 \%(\%)$;

$\mathrm{V}_{6}$ é o volume da descarga igual a seis litros;

$\alpha_{3}$ representa a porcentagem de utilizações da descarga de três litros, que pode ser de $90 \%, 70 \%$ e $50 \%(\%)$; e

$\mathrm{V}_{3}$ é o volume da descarga igual a três litros.

Para as torneiras e mictórios, usaram-se ambas as tecnologias: sensor de presença e fechamento automático. No entanto, para estimar o percentual de redução do consumo das torneiras e mictórios utilizou-se a base de dados encontrada nos mais diversos fabricantes desses tipos de tecnologias. Para estimar a redução do consumo de água pela troca de torneiras e mictórios para ambas as tecnologias supracitadas, utilizou-se a Equação 9.

$\mathrm{C}_{\text {novo }}=\mathrm{C}_{\text {aparelho }}-(P R *$ Caparelho $)$

Eq. 9

Onde:

$\mathrm{C}_{\text {novo }}$ representa o novo consumo da torneira ou mictório (litros/dia);

$\mathrm{C}_{\text {aparelho }}$ é o consumo total da torneira ou mictório antigo (litros/dia); e

PR é o percentual de redução do aparelho economizador verificado nas informações dos fabricantes $(\%)$.

\section{Conjugação de alternativas}

A fim de estimar o potencial de redução total por meio das estratégias propostas, fez-se a combinação das alternativas. Assim, criaram-se três cenários de conjugação, apresentados na Tabela 1.

\begin{tabular}{|l|l|}
\hline \multicolumn{1}{|c|}{$\begin{array}{c}\text { Cenários de conjugação das } \\
\text { alternativas }\end{array}$} & \multicolumn{1}{c|}{ Funcionamento } \\
\hline $\begin{array}{l}\text { Reúso de águas cinzas }+ \\
\text { aproveitamento de água pluvial }\end{array}$ & $\begin{array}{l}\text { A demanda por água não potável remanescente ao } \\
\text { reúso de águas cinzas poderá ser suprida } \\
\text { separadamente com o aproveitamento de água } \\
\text { pluvial para fins não potáveis (bacias sanitárias, } \\
\text { mictórios e limpeza) }\end{array}$ \\
\hline $\begin{array}{l}\text { Equipamentos economizadores }+ \\
\text { aproveitamento de água pluvial }\end{array}$ & $\begin{array}{l}\text { A água pluvial substituirá o uso de água potável } \\
\text { em fins não potáveis }\end{array}$ \\
\hline $\begin{array}{l}\text { Equipamentos economizadores }+ \\
\text { reúso de águas cinzas }+\end{array}$ & $\begin{array}{l}\text { A demanda por água não potável remanescente } \\
\text { aproveitamento de água pluvial ser suprida com o aproveitamento de água } \\
\text { pluvial para fins não potáveis }\end{array}$ \\
\hline
\end{tabular}

Tabela 1 - Cenários de conjugação das alternativas de redução de consumo de água potável 


\section{Resultados}

A amostra entrevistada foi de 41 pessoas na escola municipal e de 47 pessoas na escola estadual, com o erro esperado calculado através da Equação 1 de $13,3 \%$ na escola municipal e de $13,1 \%$ na escola estadual, embora na primeira estimativa do consumo de água os valores de erros percentuais tenham sido iguais a $44,5 \%$ e a $9,2 \%$ na escola municipal e na estadual respectivamente. Essa diferença elevada na escola municipal foi causada por algumas respostas incoerentes, sobretudo dos professores.

A Tabela 2 apresenta os percentuais de participantes sobre cada público nas escolas. Destaca-se que para os públicos professores e alunos foram aplicados questionários, e para $\mathrm{o}$ público funcionários foram feitas entrevistas, pois estes apresentavam hábitos diferenciados no que tange ao cotidiano das atividades nas escolas. A amostra de alunos, embora pequena comparada ao número total de alunos das escolas, mostrou bons resultados, como será mostrado mais adiante.

Os questionários foram aplicados a 25 alunos $(19 \%)$ das turmas de $3^{3}$ série e $4^{\mathrm{a}}$ série (período matutino) na escola municipal, e a 31 alunos (14\%) das turmas de $4^{\mathrm{a}}$ série e $5^{\mathrm{a}}$ série (período vespertino) na escola estadual. Esses percentuais participantes de efetivos são menores para esse público, pois se considerou apenas uma parcela da população, estudantes com 8 a 12 anos de idade.

\section{Consumo medido e primeira estimativa}

Nas Figuras 1 e 2 pode ser observado o consumo mensal das escolas, destacando-se o período de férias e o letivo. $\mathrm{O}$ consumo medido obtido através das contas de água revela que os consumos nas instituições são próximos, embora a escola estadual tenha aproximadamente 100 pessoas a mais.

Para a escola estadual o consumo no período de férias foi apenas $0,8 \mathrm{~m}^{3} /$ mês menor do que o consumo médio mensal no período letivo; e para a escola municipal essa diferença foi de $3,4 \mathrm{~m}^{3} / \mathrm{mês}$ a mais no período letivo. Assim, constatou-se que, para as escolas analisadas, os períodos de férias não indicaram redução significativa no consumo de água, pois nesses períodos foram feitas limpezas em larga escala, envolvendo um consumo excessivo de água.

Tabela 2 - Percentual de participantes sobre cada público nas escolas

\begin{tabular}{llccc}
\hline Escola & Público & No de pessoas participantes & No total de pessoas do público & Percentual (\%) \\
\hline \multirow{4}{*}{ Municipal } & Professores & 11 & 12 & 92 \\
& Funcionários & 5 & 5 & 100 \\
& Alunos & 25 & 132 & 19 \\
\cline { 2 - 5 } Estadual & Total & $\mathbf{4 1}$ & $\mathbf{1 4 9}$ & $\mathbf{2 8}$ \\
\hline \multirow{5}{*}{ Professores } & 11 & 18 & 61 \\
& Funcionários & 5 & 5 & 100 \\
& Alunos & 31 & 220 & 14 \\
\hline & Total & $\mathbf{4 7}$ & $\mathbf{2 4 3}$ & $\mathbf{1 9}$ \\
\hline
\end{tabular}

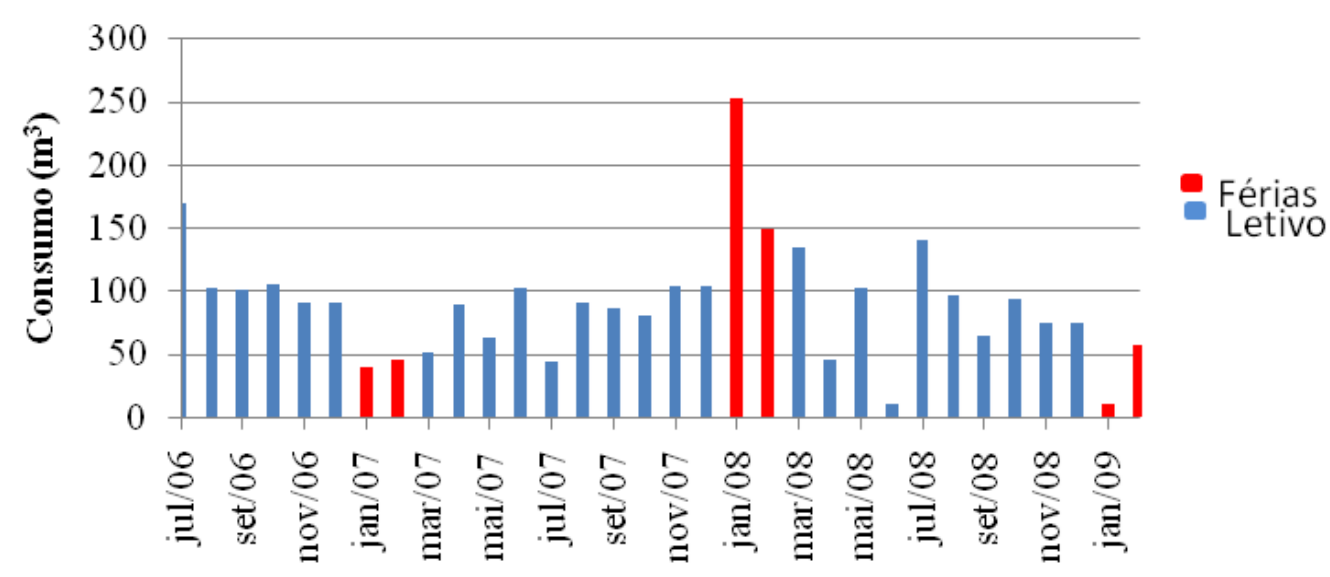

Figura 1 - Consumo mensal de água medido na escola municipal

72 Fasola, G. B.; Ghisi, E.; Marinoski, A. K.; Borinelli, J. B. 


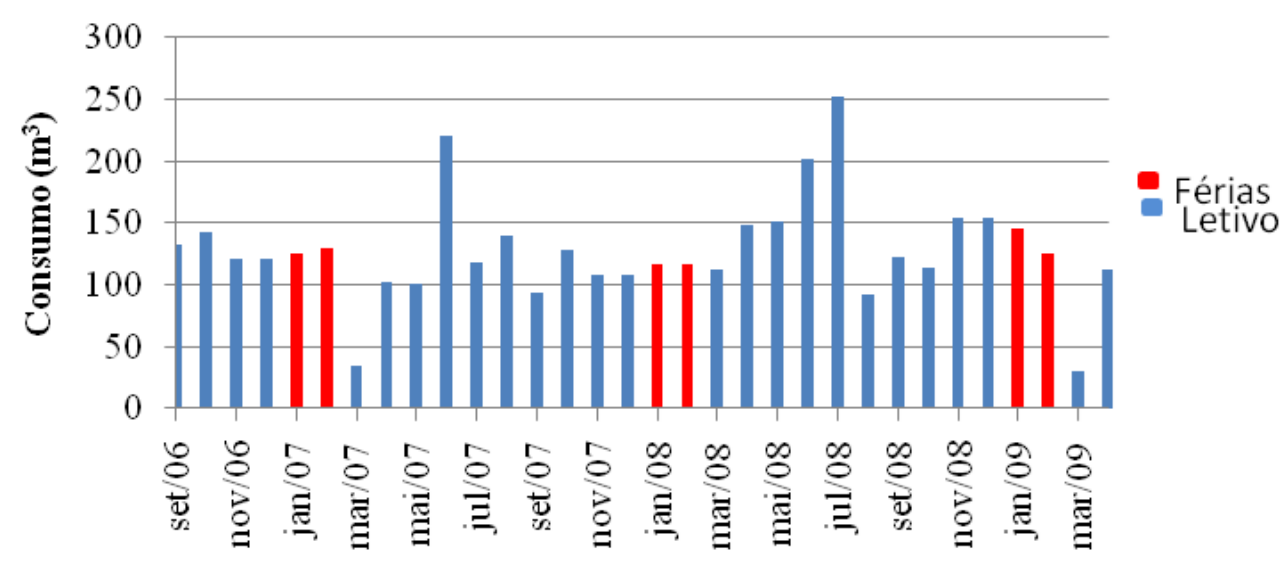

Figura 2 - Consumo mensal de água medido na escola estadual

Tabela 3 - Comparação entre consumo medido e consumo estimado

\begin{tabular}{|c|c|c|c|c|c|}
\hline Escola & Consumos & Medido & Estimado & Diferença (\%) & Diferença (L) \\
\hline \multirow{3}{*}{ Municipal } & Diário $\left(\mathrm{m}^{3} / \mathrm{dia}\right)$ & 4,3 & 6,2 & 44,5 & $1.908,4$ \\
\hline & Mensal (m³/mês) & 89,1 & 128,7 & 44,5 & $39.598,2$ \\
\hline & Por usuário (L/dia) & 28,8 & 41,6 & 44,5 & 12,8 \\
\hline \multirow{3}{*}{ Estadual } & Diário $\left(\mathrm{m}^{3} / \mathrm{dia}\right)$ & 6,1 & 6,7 & 9,2 & 565,9 \\
\hline & Mensal (m³/mês) & 127,5 & 139,2 & 9,2 & $11.743,3$ \\
\hline & Por usuário (L/dia) & 25,3 & 27,6 & 9,2 & 2,3 \\
\hline
\end{tabular}

Então, considerando apenas o período letivo, fezse a primeira estimativa de consumo de água para as escolas. A Tabela 3 mostra os resultados, que são comparados ao consumo medido.

Evidencia-se uma substancial diferença quanto à medição na escola municipal. Essa diferença provém essencialmente de respostas incoerentes de alguns professores a respeito da frequência e do tempo de uso das bacias sanitárias, como acionamentos da descarga por 15 segundos e uso médio do banheiro 10 vezes ao dia. Sendo assim, a escola municipal foi submetida ao processo de análise de sensibilidade, como é exposto no item a seguir. Os consumos específicos desta primeira estimativa podem ser vistos na Tabela 3 , onde já são comparados aos valores finais corrigidos.

\section{Análise de sensibilidade}

Anteriormente ao processo de análise de sensibilidade na escola municipal, fez-se uma adequação do consumo diário de cada professor, devido às incoerências observadas nas respostas das entrevistas. Com a primeira estimativa obtevese um índice de consumo de 77,7 litros/dia.professor, muito acima da média por pessoa e muito acima da média dos professores da escola estadual. Sendo assim, essa média diária de consumo por professor foi igualada ao consumo médio medido para a escola, ou seja, 28,8 litros/dia.professor. Ainda com essa aproximação, a escola necessitou adequação entre o consumo estimado e o medido, por apresentar um erro percentual de $30,8 \%$ para mais.

A partir disso, iniciou-se o processo de análise de sensibilidade com a identificação dos aparelhos mais sensíveis, sendo eles, em primeiro, a torneira da cozinha e, em segundo, a bacia sanitária. Logo, esse erro percentual foi reduzido proporcionalmente para esses dois aparelhos.

\section{Usos finais corrigidos}

Os consumos específicos corrigidos, ou seja, os consumos separados por atividade consumidora estão apresentados nas Tabelas 4 e 5 para as escolas. Na coluna "Final", estão representados os consumos corrigidos após a análise de sensibilidade e, na coluna representada por “Anterior", a primeira estimativa realizada.

As Tabelas 4 e 5 mostram algumas diferenças nos consumos entre funcionários, alunos e professores na mesma escola, e quando comparadas as duas escolas. Isso se explica pela jornada de trabalho distinta nas escolas.

Os usos finais corrigidos, após a análise de sensibilidade, em ambas as escolas podem ser vistos na Tabela 6 . 
Tabela 4 - Consumos diários específicos de água corrigidos na escola municipal

\begin{tabular}{lccrr}
\hline \multirow{2}{*}{ Atividade } & \multicolumn{2}{c}{ Consumo (L/dia.usuário) } & \multicolumn{2}{c}{ Consumo total (L/dia) } \\
\cline { 2 - 5 } & Anterior & Final & Anterior & \multicolumn{1}{c}{ Final } \\
\hline Limpeza & $2,0^{1}$ & $2,0^{1}$ & 265,4 & 265,4 \\
Cozinha & $35,1^{2}$ & $22,4^{2}$ & $3.983,5$ & $2.954,5$ \\
Professores & 77,7 & 23,2 & 932,1 & 278,2 \\
Funcionários & 10,5 & 8,0 & 52,3 & 40,2 \\
Alunos & 8,5 & 5,7 & 967,9 & 754,6 \\
Total & - & - & $\mathbf{6 . 2 0 1 , 2}$ & $\mathbf{4 . 2 9 2 , 9}$ \\
\hline
\end{tabular}

Nota: ${ }^{1} \mathrm{e}^{2}$ Consumo da limpeza dividido pelo total de alunos.

Tabela 5 - Consumos diários específicos de água corrigidos na escola estadual

\begin{tabular}{lcccc}
\hline \multirow{2}{*}{ Atividade } & \multicolumn{2}{c}{ Consumo (L/dia.usuário) } & \multicolumn{2}{c}{ Consumo total (L/dia) } \\
\cline { 2 - 5 } & Anterior & Final & Anterior & Final \\
\hline Limpeza & $1,3^{1}$ & $1,3^{1}$ & 280,0 & 280,0 \\
Cozinha & $8,2^{2}$ & $8,2^{2}$ & $1.486,7$ & $1.486,7$ \\
Mictório & - & - & $2.880,0$ & 2314,1 \\
Professores & 25,9 & 25,9 & 465,3 & 465,3 \\
Funcionários & 50,8 & 50,8 & 253,9 & 253,9 \\
Alunos & 7,4 & 7,4 & $1.342,8$ & $1.342,8$ \\
Total & - & - & $\mathbf{6 . 7 0 8 , 7}$ & $\mathbf{6 . 1 4 2 , 7}$ \\
\hline
\end{tabular}

Nota: ${ }^{1} \mathrm{e}^{2}$ Consumo da limpeza dividido pelo total de alunos.

Tabela 6 - Usos finais de água corrigidos para as escolas municipal e estadual

\begin{tabular}{lcccc}
\hline \multirow{2}{*}{ Aparelho } & \multicolumn{2}{c}{ Escola Municipal } & \multicolumn{2}{c}{ Escola Estadual } \\
& Consumo (L/dia) & Percentual (\%) & Consumo (L/dia) & Percentual (\%) \\
\hline Torneiras de banheiro & 166,6 & 3,9 & 187,2 & 3,1 \\
Bacias sanitárias & 841,2 & 19,6 & $1.830,1$ & 29,8 \\
Mictório & 14,1 & 0,3 & $2.314,1$ & 37,7 \\
Limpeza (torneira ${ }^{1}$ ) & 265,4 & 6,2 & 280,0 & 4,5 \\
Cozinha (torneira) & $2.954,5$ & 68,8 & $1.486,7$ & 24,2 \\
Bebedouro & 51,0 & 1,2 & 44,7 & 0,7 \\
Total & $\mathbf{4 . 2 9 2 , 9}$ & $\mathbf{1 0 0 , 0}$ & $\mathbf{6 1 4 2 , 7}$ & $\mathbf{1 0 0 , 0}$ \\
Consumo per capita & $\mathbf{2 8 , 1}$ & - & $\mathbf{2 5 , 3}$ & - \\
\hline
\end{tabular}

Nota: 1 Para a escola municipal, a limpeza inclui também o consumo de uma máquina de lavar roupas.

Pode-se destacar como principal consumidor de água a elaboração das refeições diárias para os alunos da escola municipal e, em seguida, a descarga da bacia sanitária. Na escola estadual, o maior consumidor foi o mictório, mas isso ocorre devido ao fluxo de água contínuo, ou seja, o usuário não tem autonomia para ativar o despejo de água. Além disso, é importante ressaltar que a escola estadual, diferentemente da escola municipal, não oferecia almoço para os alunos; oferecia apenas lanches prontos, como bolachas ou bolos, o que influencia muito no consumo de água potável.

Agrupando os dados da Tabela 6 de modo a gerar um gráfico, as Figuras 3(a) e 3(b) apresentam o consumo total potável e não potável em termos percentuais, e pode-se observar que existe um elevado consumo de água não potável, o que representa um ótimo potencial de economia. Não é possível, no entanto, estabelecer um consumo médio de água não potável devido aos valores serem muito díspares, o que confirma a necessidade de mais estudos em outras escolas.

\section{Estratégias para a redução do consumo de água potável}

Com consumo total de água estimado igual ao medido e todos os ajustes feitos após a análise de sensibilidade e usos finais corrigidos, pode-se propor estratégias para a redução no consumo de água potável das escolas.

74 Fasola, G. B.; Ghisi, E.; Marinoski, A. K.; Borinelli, J. B. 


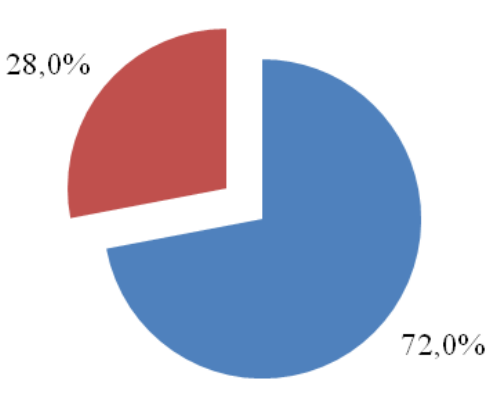

Uso não potável Uso potável

(a) Escola estadual

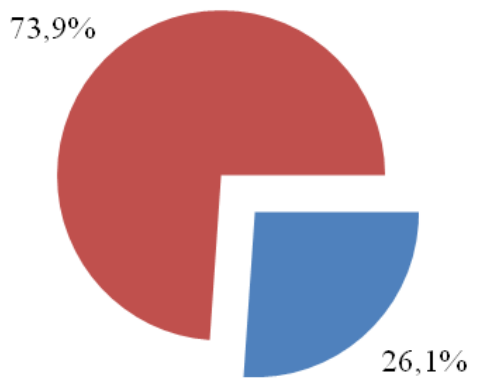

- Uso não potável Uso potável

(b) Escola municipal

Figura 3 - Consumo total potável e não potável nas escolas

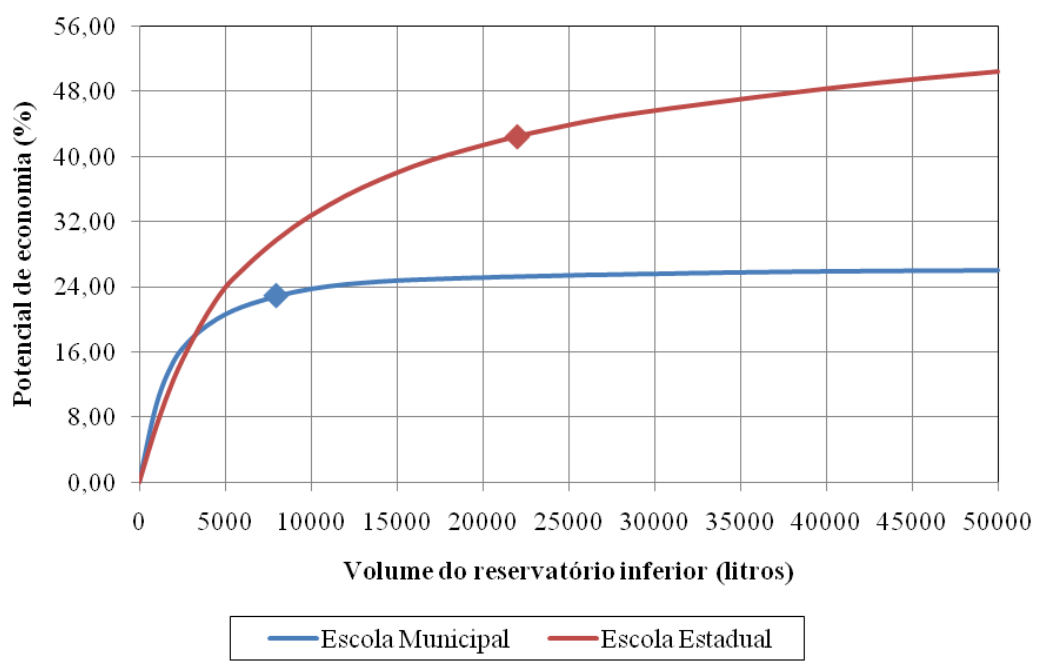

Figura 4 - Potencial de economia de água potável versus volume do reservatório inferior para as escolas municipal e estadual ao se considerar o aproveitamento de água pluvial

Tabela 7 - Dados inseridos no programa Netuno 2.1

\begin{tabular}{|c|c|c|c|c|}
\hline \multirow{3}{*}{$\begin{array}{l}\text { Dados de entrada para o Netuno } 2.1 \\
\text { Dados pluviométricos } \\
\text { Área de captação }\left(\mathrm{m}^{2}\right) \\
\end{array}$} & \multicolumn{2}{|c|}{ Escola Municipal } & \multicolumn{2}{|c|}{ Escola Estadual } \\
\hline & \multicolumn{4}{|c|}{ Florianópolis (2000 a 2006) } \\
\hline & 638 & & 800 & \\
\hline \multirow{2}{*}{ Demanda variável (L/dia.pessoa) } & Seg. a Sex. & 28,8 & Seg. a Sex. & 25,3 \\
\hline & Sáb. e Dom. & 0 & Sáb. e Dom. & 0 \\
\hline Número de pessoas & 149 & & 243 & \\
\hline $\begin{array}{l}\text { Porcentagem de água potável a ser substituída por pluvial } \\
(\%)\end{array}$ & 26,1 & & 72,0 & \\
\hline Coeficiente de aproveitamento & 0,8 & & 0,8 & \\
\hline Reservatório superior (litros) & $2.000^{*}$ & & $5.000^{*}$ & \\
\hline Cálculo para diversos reservatórios inferiores & Sim & & Sim & \\
\hline Volume máximo do reservatório inferior (litros) & 50.000 & & 50.000 & \\
\hline Intervalo entre volumes do reservatório inferior (litros) & 1.000 & & 1.000 & \\
\hline $\begin{array}{l}\text { Diferença entre potenciais de economia para estimativa do } \\
\text { volume do reservatório inferior }(\%)\end{array}$ & 0,5 & & 0,5 & \\
\hline
\end{tabular}

Nota:* Valor superior à demanda total de água não potável e mais próximo do comercialmente vendido. 
Analisou-se, primeiro, o potencial de redução através do aproveitamento de água pluvial, que, com o auxílio do programa Netuno 2.1, forneceu um potencial de economia igual a $22,9 \%$ para a escola municipal e de $42,5 \%$ para a escola estadual, como indicado na Figura 4. Esse valor é bem significativo, mas seria interessante avaliar o custo-benefício na construção dos reservatórios, porque os volumes dimensionados foram grandes, $8 \mathrm{~m}^{3}$ e $22 \mathrm{~m}^{3}$, respectivamente, para as escolas municipal e estadual.

Os dados de entrada utilizados para a simulação podem ser observados na Tabela 7 , e o resultado pode ser visualizado na Figura 4, para as escolas.

$\mathrm{Na}$ redução de consumo de água mediante a instalação de equipamentos economizadores, os percentuais foram mais satisfatórios, alcançando $15,3 \%$ para a escola municipal e $55,9 \%$ para a escola estadual. Os percentuais de redução supracitados são provenientes do cenário mostrado na Tabela 8, onde se considerou como melhor tecnologia a de sensor de presença, e o melhor desempenho, o fornecido pelos fabricantes pesquisados. A diferença percentual que ocorreu entre as escolas para essa alternativa se deve porque na escola estadual o consumo do mictório deixou de ser contínuo para funcionar com equipamentos economizadores.

Para a estratégia de redução de consumo através de reúso de águas cinzas, o potencial foi muito inferior, ou seja, apenas 5,1\% para a escola municipal e $4,2 \%$ para a escola estadual, como indica a Tabela 8 .

Entre as combinações, a que demonstrou melhor resultado foi a de equipamentos economizadores, seguida pelo aproveitamento de água pluvial. Essa alternativa atingiu um potencial de redução de $27,8 \%$ e $72,7 \%$, respectivamente, para as escolas municipal e estadual. Além desse elevado potencial, essa alternativa possui outra vantagem, a facilidade para executar as estratégias separadamente.

Para facilitar a visualização dos resultados obtidos, estruturou-se a Tabela 9, que resume todas as estratégias e seus respectivos desempenhos. É possível observar que a combinação de equipamentos economizadores com aproveitamento de água pluvial surtiu melhores resultados. A instalação de equipamentos economizadores, reúso de águas cinzas e aproveitamento de água pluvial não foi estimada devido à pouca oferta de águas cinzas.

Tabela 8 - Índices de economia utilizados em aparelhos economizadores para a obtenção dos percentuais de redução nas escolas

\begin{tabular}{lcc}
\hline Aparelho sanitário & Troca & Percentual de redução (\%) \\
\hline Torneias de banheiro & Comum para sensorial & 77 \\
Torneias de banheiro & Automática para sensorial & 48 \\
Mictórios & Comum para sensorial & 80 \\
Bacias sanitárias & Existente para descarga dual & $\alpha_{6}=10 \% ; \alpha_{3}=90 \% *$ \\
\hline
\end{tabular}

Nota:*Índices utilizados na Equação 9.

Tabela 9 - Resumo dos resultados de potencial de economia de água potável para diferentes estratégias para as duas escolas

\begin{tabular}{lcc}
\hline & \multicolumn{2}{c}{ Potencial de economia (\%) } \\
\cline { 2 - 3 } Estratégia & $\begin{array}{c}\text { Escola } \\
\text { Municipal }\end{array}$ & $\begin{array}{c}\text { Escola } \\
\text { Estadual }\end{array}$ \\
\hline Aproveitamento de água pluvial & 22,9 & 42,5 \\
Reúso de águas cinzas & 5,1 & 4,2 \\
Instalação de equipamentos economizadores & $15,3^{*}$ & $55,9 *$ \\
Reúso de águas cinzas + aproveitamento de água & 24,0 & 46,3 \\
pluvial & & \\
Instalação de equipamentos economizadores + & 27,8 & 72,7 \\
aproveitamento de água pluvial & & \\
\hline
\end{tabular}

Nota: * Percentual referente ao cenário com melhor desempenho

76 Fasola, G. B.; Ghisi, E.; Marinoski, A. K.; Borinelli, J. B. 


\section{Conclusões}

Percebe-se com o fim da pesquisa como se distribui o consumo de água em duas escolas do município de Florianópolis. Os índices de consumo por pessoa foram semelhantes em ambas as escolas; na escola municipal foi de 28,8 litros/dia.pessoa, e na Estadual, de 25,3 litros/dia.pessoa.

Assim como em outras tipologias de edificação, e até mesmo em escolas, obteve-se como resultado que um dos aparelhos sanitários que consome maior quantidade de água é a bacia sanitária, chegando a $29,8 \%$ na escola estadual e a $19,6 \%$ na escola municipal, embora na escola estadual o maior consumo de água não potável tenha sido proveniente do mictório, que correspondeu a $37,7 \%$

No que diz respeito às estratégias para redução do consumo de água potável, o aproveitamento de água pluvial é uma alternativa que promove um bom potencial de economia. Isso porque Florianópolis é uma cidade litorânea e de clima temperado, onde as chuvas durante o ano são bem regulares, com maior precipitação nos meses entre setembro e março. Esse é um dos principais motivos que tornam o aproveitamento de água pluvial uma alternativa vantajosa.

O reúso de água mostrou-se uma estratégia inviável, pois não existiam aparelhos que ofertassem grande volume de efluentes, como chuveiros ou máquinas de lavar roupas. Além disso, os volumes disponíveis, como os provenientes das torneiras de banheiro, também eram irrisórios, se comparados ao consumo de água não potável.

Os aparelhos economizadores tornaram-se a segunda alternativa mais viável. Apresentaram redução satisfatória na escola municipal e excelente na escola estadual.

A combinação que produziu melhor potencial de economia de água potável foi a instalação de equipamentos economizadores em conjunto com o aproveitamento de água pluvial, chegando a 27,8\% na escola municipal e a $72,7 \%$ na escola estadual. Tais potenciais de economia são maiores do que os usos não potáveis de cada escola, pois o uso de equipamentos economizadores considera também as torneiras, em que há uso de água potável. Logo, o potencial de economia pode ser maior do que o uso final de água não potável.

No entanto, salienta-se que a escola estadual apresentou elevado consumo de água nos mictórios, fora do padrão esperado, o que acabou amplificando o potencial de economia de água potável obtido com a combinação de aproveitamento de água pluvial e instalação de aparelhos economizadores.

Os resultados sobre usos finais apresentaram diferenças substanciais entre as duas escolas. Por isso, há necessidade de mais pesquisas voltadas a essa tipologia, não só em Florianópolis, mas também em outras cidades do Brasil.

\section{Referências}

\author{
ASSOCIAÇÃO BRASILEIRA DE NORMAS \\ TÉCNICAS. NBR 5626: instalação predial de \\ água fria. Rio de Janeiro, 1998.
}

AGÊNCIA NACIONAL DE ÁGUAS. Conservação e Reúso da Água em Edificações. São Paulo: Prol, 2005. 152 p.

ANDRADE, M.; MARINOSKI, A. K.; BECKER, H. R. Sistemas de Aproveitamento de Água de Chuva. Casa Eficiente: uso racional da água. 2010.

BARBETTA, P. A. Estatística Aplicada às Ciências Sociais. Florianópolis: Ed. da UFSC, 2003.

BARRETO, D. Perfil do Consumo Residencial e Usos Finais de Água. Ambiente Construído, Porto Alegre, v. 8, n. 2, p. 23-40, abr./jun. 2008.

FONINI, A.; FERNANDES, V. M. C.; PIZZO, H. S. Estudo para Determinação da Capacidade de Reúso das Águas Pluviais e das Águas Cinzas em Um Complexo Esportivo Universitário. In: CONFERÊNCIA LATINO-

AMERICANA DE CONSTRUÇÃO

SUSTENTÁVEL, 1.; ENCONTRO

NACIONAL DE TECNOLOGIA DO

AMBIENTE CONSTRUÍDO, 10., São Paulo, SP. Anais... São Paulo, 2004.

GHISI, E. Potential for Potable Water Savings by Using Rainwater in the Residential Sector of Brazil. Building and Environment, v. 41, n. 11, p. 1544-1550, 2006.

GHISI, E.; CORDOVA, M. M.; ROCHA, V. L. Netuno 2.1. Programa computacional. Universidade Federal de Santa Catarina, Departamento de Engenharia Civil. Disponível em:

$<$ http://www.labeee.ufsc.br/downloads/softwar es/netuno $>$. Acesso em: 10 jul. 2009.

GHISI, E.; MARINOSKI, A. K.

Aproveitamento de Água Pluvial para Usos

Não Potáveis em Instituição de Ensino: estudo de caso em Florianópolis, SC. Ambiente Construído, Porto Alegre, v. 8, n. 2, p. 18, abr./jun. 2008. 
GHISI, E.; OLIVEIRA, S. M. Potential for Potable Water Savings by Combining the Use of Rainwater and Greywater in Houses in Southern Brazil. Building and Environment, v. 42, n. 4, p. 1731-1742, 2007.

GONÇALVES, O. M. et al. Indicadores de Uso Racional da Água para Escolas de Ensino Fundamental e Médio. Ambiente Construído, Porto Alegre, v. 5, n. 3, p. 63, jul./set. 2005.

GONÇALVES, R. F. Uso Racional da Água em Edificações. Rio de Janeiro: Abes, 2006.

MANO, R. S.; SCHMITT, C. M. Captação Residencial de Água Pluvial, para Fins Não Potáveis, em Porto Alegre: aspectos básicos da viabilidade técnica e dos benefícios do sistema. In: CONFERÊNCIA LATINO-AMERICANA DE CONSTRUÇÃO SUSTENTÁVEL, 1.; ENCONTRO NACIONAL DE TECNOLOGIA DO AMBIENTE CONSTRUÍDO, 10., São Paulo, SP, 2004. Anais... São Paulo, 2004.

PETERS, M. R. et al. Potencialidade de Reúso Residencial Utilizando Fontes Alternativas de Água. In: SIMPÓSIO ÍTALO BRASILEIRO DE ENGENHARIA SANITÁRIA E AMBIENTAL, 8., Fortaleza, 2006. Anais... Fortaleza, 2006.

PHILIPPI, L. S. et al. Reúso Combinado de Águas Cinzas (Grey Water) e Água de Chuva em Uma Unidade Residencial. Campo Grande: ABES, 2005.

PROGRAMA DE PESQUISAS EM

SANEAMENTO BÁSICO. Rede Cooperativa de Pesquisas. Tecnologias de Segregação e

Tratamento de Esgotos Domésticos na Origem, Visando a Redução do Consumo de Água e da Infra-Estrutura de Coleta, Especialmente nas Periferias Urbanas. Vitória: UFES, UFSC, UNICAMP, IPT, 2006.

\section{SAUTCHÚK, C. A. Código de Prática de} Projeto de Execução de Sistemas Prediais: conservação de água em edifícios. Brasília, DF: Programa Nacional de Combate ao Desperdício de Água - DTA. Documento Técnico de Apoio n ${ }^{\mathrm{o}}$ F3. 2004.
SIMIONI, W. I.; GHISI, E.; GÓMEZ, L. A. Potencial de Economia de Água Tratada Através do Aproveitamento de Águas Pluviais em Postos de Combustíveis: estudos de caso. In: Conferência Latino-Americana de Construção Sustentável, 1.; Encontro Nacional de Tecnologia do Ambiente Construído, 10., São Paulo, 2004. Anais... São Paulo: Entac, 2004.

TOMAZ, P. Aproveitamento de Água de Chuva: para áreas urbanas e fins não-potáveis. São Paulo: Navegar, 2003.

\section{UNITED NATIONS ENVIRONMENT} PROGRAMME. Global Environment Outlook 3: past, present and future perspectives. Earthscan, United Kingdon, 2002.

YWASHIMA, L. A. Avaliação do Uso de Água em Edifícios Escolares Públicos e Análise de Viabilidade Econômica da Instalação de Tecnologias Economizadoras nos Pontos de Consumo. Dissertação (Mestrado em Engenharia Civil) - Faculdade de Engenharia Civil, Arquitetura e Urbanismo; Universidade Estadual de Campinas, Campinas, 2005.

YWASHIMA, L. A. et al. Método para Avaliação da Percepção dos Usuários para o Uso Racional de Água em Escolas. In: CONFERÊNCIA LATINO-AMERICANA DE CONSTRUÇÃO SUSTENTÁVEL, 1.; ENCONTRO NACIONAL DE TECNOLOGIA DO AMBIENTE CONSTRUÍDO, 11., São Paulo, 2006. Anais... São Paulo: Entac, 2006.

WERNECK, G. A. M.; BASTOS, L. E. G. A Água da Chuva Como Fonte de Recursos Hídricos para as Escolas de Barra do Piraí e os Reflexos Para o Sistema Municipal de Abastecimento. In: Conferencia LatinoAmericana de Construção Sustentável, 1.; Encontro Nacional de Tecnologia do Ambiente Construído, 11., São Paulo. Anais... São Paulo: Entac, 2006.

Revista Ambiente Construído

Associação Nacional de Tecnologia do Ambiente Construído

Av. Osvaldo Aranha, 99 - 30 andar, Centro Porto Alegre - RS - Brasil CEP 90035-190

Telefone: +55 (51) 3308-4084 Fax: +55 (51) 3308-4054

www. seer.ufrgs. br/ ambienteconstruido

E-mail: ambienteconstruido@ufrgs.br

78 Fasola, G. B.; Ghisi, E.; Marinoski, A. K.; Borinelli, J. B. 